\title{
Small dolphins in a small sea: age, growth and life-history aspects of the Black Sea common bottlenose dolphin Tursiops truncatus
}

\author{
Pavel Gol'din ${ }^{1, *}$, Elena Gladilina ${ }^{2}$ \\ ${ }^{1}$ Schmalhausen Institute of Zoology, National Academy of Sciences of Ukraine, 15 Bogdan Khmelnytskyi Street, Kiev, \\ 01601 Ukraine \\ ${ }^{2}$ National Reserve of Chersonesus Taurica, 1 Drevnyaya Street, Sevastopol, 99045 Ukraine
}

\begin{abstract}
We provide first data on the life span, growth and seasonal aspects of the life history of Black Sea bottlenose dolphins Tursiops truncatus in the wild and compare these with historical data and conspecific populations in other geographical regions. Average life span is 20 to $32 \mathrm{yr}$; the oldest record is $41 \mathrm{yr}$. The reproductive season lasts at least from February to September or October and includes the coldest months of the year (February and March). Average adult body lengths are $240 \pm 14 \mathrm{~cm}$ for females and $255 \pm 10 \mathrm{~cm}$ for males. Rapid early body growth ceases by 3 to 4 yr. Two morphs, one large (offshore) and one small (coastal), possibly co-exist in the Black Sea. The larger morph may include winter-breeding migrants or immigrants from the Mediterranean Sea. The small coastal form is similar in body size and growth patterns to coastal populations in the eastern Mediterranean region and the Gulf of Mexico, but is characterized by early growth to maturity and small asymptotic body size. Small-sized dolphin populations in enclosed water bodies can be treated as an example of the 'island rule', and their dwarfism may hypothetically be explained as an effect of smaller prey size.
\end{abstract}

KEY WORDS: Bottlenose dolphin $\cdot$ Black Sea $\cdot$ Dwarfism $\cdot$ Life history $\cdot$ Island rule

\section{INTRODUCTION}

The common bottlenose dolphin Tursiops truncatus (Montagu, 1821) is a widely distributed polymorphic species known for its high geographical and ecological variation in body size and life-history strategies (Mead \& Potter 1990, Wells \& Scott 1999). Dolphins inhabiting the Black Sea, the inland water body in southeastern Europe connected with the Mediterranean Sea, are notable for their small body size. They were denominated as a separate subspecies $T$. t. ponticus Barabash-Nikiforov, 1940, with dwarfism as the morphological argument for this taxonomy (Kleinenberg 1956, Tomilin 1957, Viaud-Martinez et al. 2008). Black Sea bottlenose dolphins were extensively harvested in the first half of the 20th century, and their morphological characteristics were reported in detail, based on taken animals

\footnotetext{
*Corresponding author: pavelgoldin412@gmail.com
}

(Barabash-Nikiforov 1940, Kleinenberg 1956, Tomilin 1957). However, little is known about many age aspects of Black Sea bottlenose dolphin biology. Most data has come from research on animals in captivity (Ozharovskaya 1997, Bogdanova 2006) and relates to cases in which the dolphins were taken from the wild by research facilities between 1966 and 2001 and in which age was estimated from body size and external appearance. In addition, there have been some studies of age identified from growth layers in teeth of a few wild animals (Karaçam et al. 1990, Glazov \& Lyamin 2000, Gol'din 2006). Here we provide for the first time data on the life span, body growth and seasonal aspects of life history of the Black Sea bottlenose dolphins in the wild and compare these data to historical data from earlier research and populations from similar habitats or neighbouring geographical areas.

() The authors 2015. Open Access under Creative Commons by Attribution Licence. Use, distribution and reproduction are unrestricted. Authors and original publication must be credited. 


\section{MATERIALS AND METHODS}

Data for this study were collected from bottlenose dolphins found dead along the coast of the Black Sea and the Sea of Azov between 1997 and 2014 and from observations at sea between 2011 and 2014 (Fig. 1). For stranded dolphins, body measurements were taken according to the scheme by Norris (1961). For age determination, longitudinal mid-sections of teeth from the middle portion of the lower jaw were used: $30-35 \mu \mathrm{m}$ sections were stained with Mayer haematoxylin and mounted on the slides enclosed in glycerin (Klevezal 1988). Ages were estimated from counting growth layer groups (GLGs) in dentine and were considered as equal to the number of complete GLGs. Animals were considered neonates (age $=0$ ) if they had teeth lacking a neonatal line in dentine or a healing umbilicus and non-erupted teeth. Animals were considered to be calves (assigned age $=0.1 \mathrm{yr}$ ) if they had a neonatal line and a small amount of postnatal dentine or healed umbilicus and nonerupted teeth. All animals younger than $3 \mathrm{yr}$ were judged to be $0.5,1.5,2.5$ yr old if they had an incomplete last GLG. The category of 'adult' animals in terms of this study includes specimens judged to be at least $10 \mathrm{yr}$ old or sexually mature animals with signs of skeletal maturity (advanced stages of epiphyseal fusion in vertebrae, complete ossification of manus or presence of prominent skull crests). Mean body lengths were used for comparison between adult animals from different geographical areas; however, upper quartiles of body length were used for samples from the West Mediterranean waters, as the upper quartiles were shown to be similar to mean adult lengths in the bottlenose dolphins from the waters of Israel (Sharir et al. 2011) and the Black Sea (present study).

Reproductive seasonality was estimated from records of stranded neonates and calves, as well as observations of mothers with neonates and calves at sea. For the observations at sea, neonates were distinguished by foetal folds (vertical lines on the body sides, often darkcoloured) and by length less than half that of the mother. In- dividuals which were less than half the length of their mothers and which showed pale vertical lines on the sides of their bodies and were relatively light in colour were classified as calves. Vertical foetal fold marks are believed to disappear within 6 wk to 3 mo after birth (Kastelein et al. 1990, Herzing 1997).

Growth curves were described using the Gompertz equation in the following form:

$$
L_{t}=L_{\infty} \cdot \mathrm{e}^{-b \mathrm{e}^{-k t}}
$$

where $L_{t}=$ length at time $t_{1} L_{\infty}=$ asymptotic length, $b=$ integration constant, $k(=g)=$ growth constant (rate of growth decay); and $t=$ time (age in yr, with birth at time 0).

Multiple normal distributions in the historical sample reported by Barabash-Nikiforov (1940) were identified using the maximum-likehood mixture analysis with the Akaike information criterion (AIC) as the indicator of the best fitting model; the procedure was performed with the PAST 3.02 software (Hammer et al. 2001).

\section{RESULTS}

In total, 80 stranded animals were examined. Age was identified in 70 specimens, body length was measured in 64 animals, and combined data on age, sex and body length were available from 43 animals.

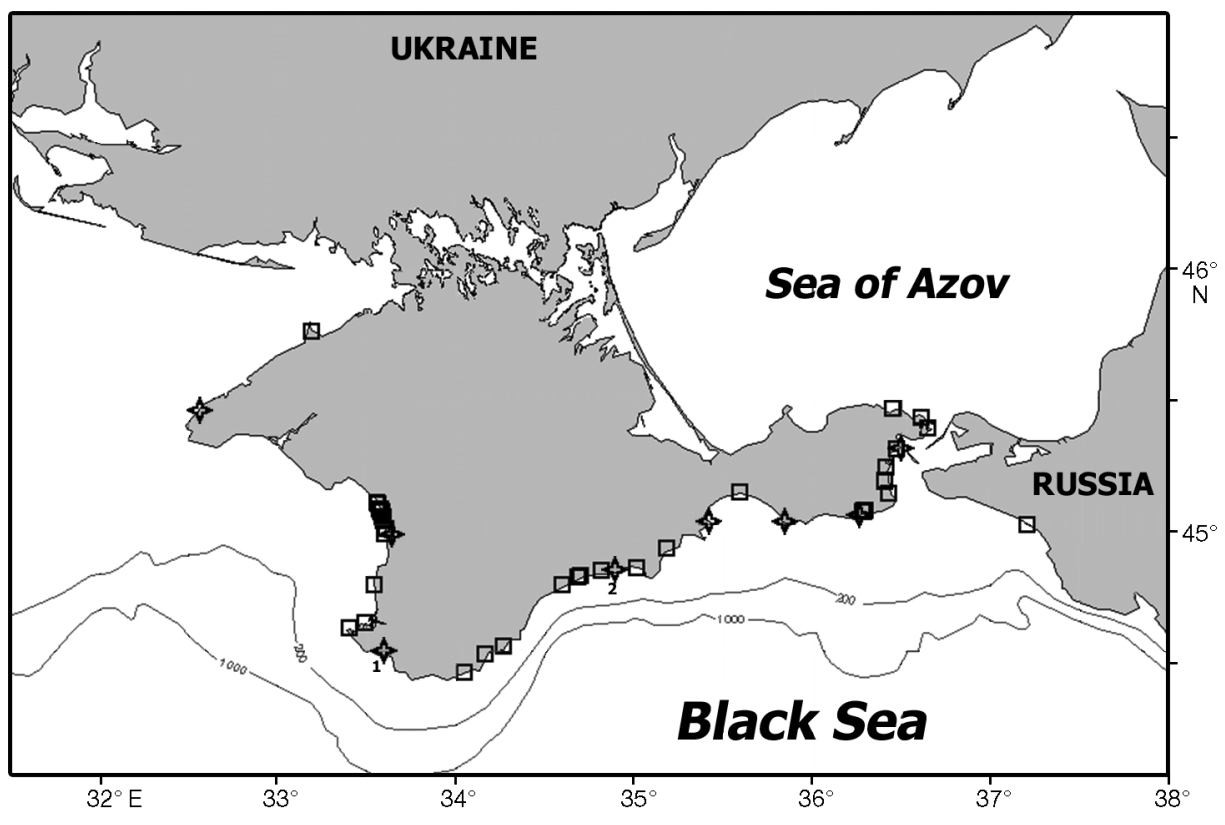

Fig. 1. Distribution of strandings (open squares) and sightings (stars) of common bottlenose dolphins in the northern Black Sea in 1997-2014. 1: Balaklava; 2: Novy Svet, the regions of regular observations at sea 


\section{Age composition of the sample}

Neonates and animals $<1 \mathrm{yr}(\mathrm{n}=17,21.2 \%)$ represented the most abundant age group in strandings (Fig. 2). Twelve animals (15.0\%) were $>20$ yr. Ninety per cent were judged to be 24 yr or younger and $95 \%$ $32 \mathrm{yr}$ or younger. Median age of adult animals was $20 \mathrm{yr}$. Thus, the average life span can be roughly estimated as $20-32$ yr. The age of the oldest animal was identified as $41 \mathrm{yr}$.

\section{Reproductive seasonality}

Two stranded females pregnant with near-term fetuses were recorded in May. Neonates were observed at sea from April to September $(n=8)$ and stranded specimens were found in April, May, June and August $(n=10)$. Calves were observed at sea from March to September $(\mathrm{n}=28)$ and stranded in April, May and July ( $n=3$ ) (Fig. 3). Given that the age of calves was estimated as $2-8 \mathrm{wk}$, the birth season lasted at least from February to September. The calving peaks were not distinct; however, a clear spring seasonality was evident in observations at sea.

\section{Growth}

Neonate body length ranged from 85 to $103 \mathrm{~cm}$ (Table 1), the measured near-term fetus was $101 \mathrm{~cm}$ in length, the shortest calf with erupted teeth was $96 \mathrm{~cm}$, and by the end of the first year of life some dolphins reached $188 \mathrm{~cm}$, twice exceeding the mean neonate size. All dolphins $>1 \mathrm{yr}$ were at least $2 \mathrm{~m}$, and at the age of $2.5 \mathrm{yr}$ some females were already larger than the smallest adults. All animals $>250 \mathrm{~cm}$ were at least $8 \mathrm{yr}$ old, and all animals $>260 \mathrm{~cm}$ were at least $20 \mathrm{yr}$ old (Fig. 4). The largest animal in our sample (male, $35 \mathrm{yr}$ ) was $270 \mathrm{~cm}$ in length. Adult animals showed statistically significant sexual dimorphism in body length (Table 1); on average, adult males were $15 \mathrm{~cm}$ longer than females (MannWhitney $U$ test, $\mathrm{p}<0.01$; $t$-test, $\mathrm{p}<0.01$ ), while young animals (yearlings) were not dimorphic. The upper quartile of the body length for the overall sample was $>250 \mathrm{~cm}$, which concurred with mean adult length.

Growth curves of both males and females in our sample are well described by a single Gompertz equation (Table 2, Fig. 4). However, both models underestimate the asymptotic lengths (definitive sizes of adult animals) by $5-7 \mathrm{~cm}$; thus, a slight secondary growth spurt is suggested after weaning and before sexual maturation. Growth rate is initially high. As predicted by Gompertz equations, females attain 0.75 of asymptotic length at $0.9 \mathrm{yr}$ and males at $1.0 \mathrm{yr} ; 0.90$ of asymptotic length at 1.7 to $1.8 \mathrm{yr}$ and 0.99 of asymptotic length at 3.7 yr. Thus, without considering a hypothetical secondary growth spurt, the definitive body size can be attained by $4 \mathrm{yr}$. As predicted by Gompertz equations, sexual dimorphism begins between 1.5 and $2 \mathrm{yr}$ when males surpass females in body length.

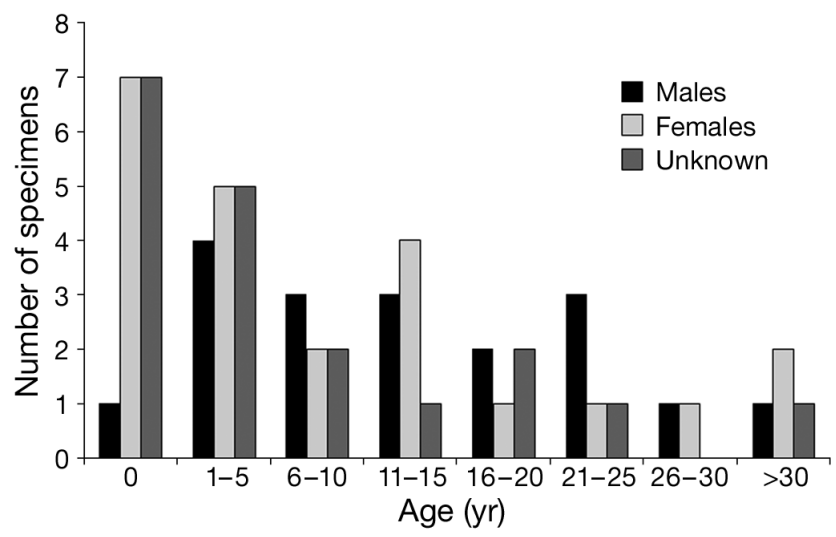

Fig. 2. Age distribution of stranded Black Sea bottlenose dolphins

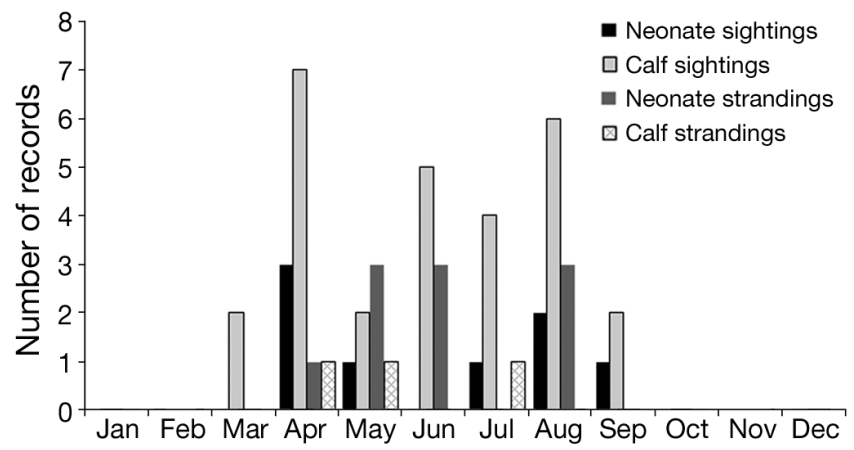

Fig. 3. Seasonal distribution of neonate and calf records of Black Sea bottlenose dolphins, sightings and strandings

Table 1. Body length $(\mathrm{cm})$ in age and sex groups of Black Sea bottlenose dolphins

\begin{tabular}{|lcrrrc|}
\hline Group & $\mathrm{n}$ & Range & Mean & $\pm \mathrm{SD}$ & $25 \% /$ Median/75\% \\
\hline Neonates & 9 & $85-103$ & 96.2 & 6.2 & $93 / 97 / 101$ \\
Adult females & 10 & $210-260$ & 240.2 & 13.8 & $235 / 237 / 250$ \\
Adult males & 16 & $241-270$ & 255.5 & 9.9 & $244 / 251 / 262$ \\
\hline
\end{tabular}




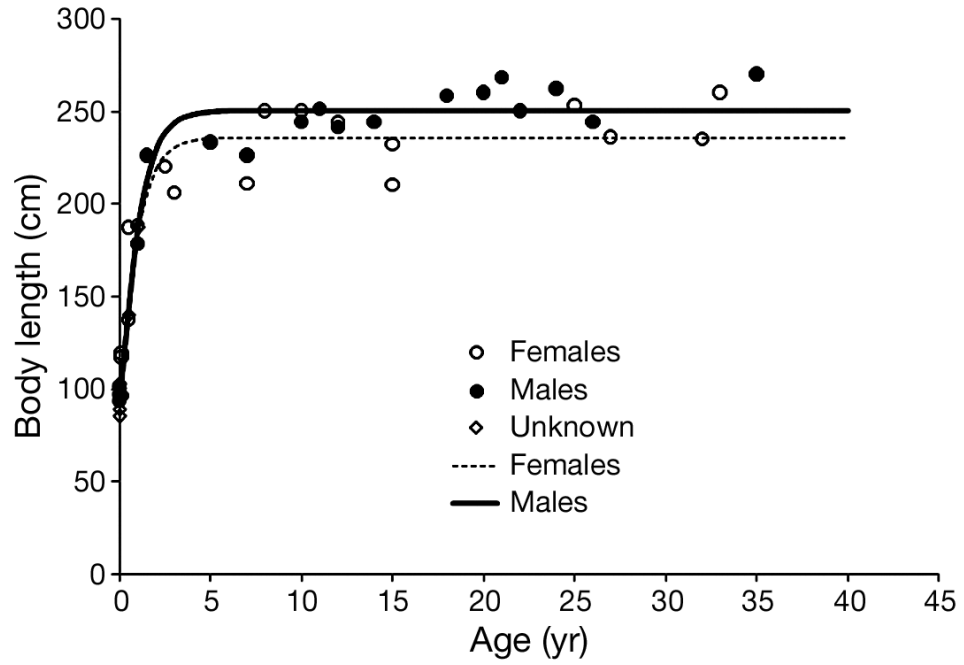

Fig. 4. Age versus body length in Black Sea bottlenose dolphins using the Gompertz growth curves

Table 2. Parameters of the Gompertz growth model for Black Sea bottlenose dolphins. $L_{\infty}$ : asymptotic length; $b$ : integration constant; $k$ : growth constant; RSS: residual sum of squares

\begin{tabular}{|lcccccc|}
\hline Sex & $\mathrm{n}$ & $L_{\infty}{ }^{2} \pm \mathrm{SE}$ & $b \pm \mathrm{SE}$ & $k \pm \mathrm{SE}$ & $\mathrm{RSS}$ & $\mathrm{R}^{2}$ \\
\hline Females & 22 & $235.8 \pm 4.8$ & $0.81 \pm 0.09$ & $1.18 \pm 0.24$ & 5234.6 & 0.91 \\
Males & 20 & $250.5 \pm 3.0$ & $1.00 \pm 0.12$ & $1.23 \pm 0.18$ & 2407.6 & 0.94 \\
\hline
\end{tabular}

+7 to $+8^{\circ} \mathrm{C}$ near the south coast of Crimea, which represents the lower limit of temperature tolerance for bottlenose dolphins (Würsig 1978). However, this apparent contradiction can be explained if we suggest a Mediterranean origin of some members of the population. The temperature of eastern Mediterranean waters in February and March ranges between 15 and $25^{\circ} \mathrm{C}$; therefore, the early reproductive seasonality may be preserved in Mediterranean immigrants despite the colder water in the Black Sea.

The maximum age recorded in our sample (41 yr) is significantly older than that $\mathrm{r}$ eported by Glazov \& Lyamin (2000) (19 yr) and Karaçam et al. (1990) (26 yr), but is similar to the estimates in other regions of the world (McFee et al. 2010).

The historical data on body size of adult Black Sea bottlenose dolphins are somewhat contradictory. Barabash-Nikiforov (1940) and Kleinenberg (1956) used the data from direct takes and reported the presence of animals as large as 310 and $330 \mathrm{~cm}$ in the Black Sea. However, the mean and median lengths of adult animals in their samples were far smaller (Fig. 5): Barabash-Nikiforov (1940) reported a mean length of $222 \mathrm{~cm}$ for fe-

\section{DISCUSSION}

\section{Historical variation and population heterogeneity}

The data on reproductive biology obtained in our study corroborate both historical data (defined here as data obtained 50 or more yr ago) and data from captivity. Kleinenberg (1956) assessed harvested specimens and reported near-term fetus size in May and June as 89 to $101 \mathrm{~cm}$. Based on data from captive animals, Ozharovskaya (1997) concluded the calving season to last from March to October with a peak in June. Reproductive seasonality in bottlenose dolphins is highly variable even in populations in close proximity: for example, in the western Gulf of Mexico calving occurs in January to March, whereas in the waters of Florida it has 2 peaks, in spring and autumn (Urian et al. 1996). However, calving is usually associated with a temperature range between 15 and $25^{\circ} \mathrm{C}$ (Würsig 1978). An unusual trait of the Black Sea dolphins documented here is the early start of the calving season, likely in February, and a spring peak in births. This is most uncommon because February and March are the coldest months in the Black Sea region with an average surface water temperature of males and $228 \mathrm{~cm}$ for males (including juveniles). Viaud-Martinez et al. (2008) examined Kleinenberg's collection of skulls taken in 1948 and concluded cranially mature animals to be 194 to $244 \mathrm{~cm}$ in length (the mean age of rostral fusion in various populations of bottlenose dolphins is 3 to $4 \mathrm{yr}$. Mead \& Potter 1990, Sharir et al. 2011). However, Kleinenberg (1956) reported greater body size from field measurements: mean length of adult females as $233 \mathrm{~cm}$ and of adult males as $275 \mathrm{~cm}$.

This difference in data can be explained if there are 2 morphs inhabiting the Black Sea, a large and a small one. Sympatric distribution of a coastal (smallsized) and an offshore (large-sized) population is usual for many delphinids (Perrin 1984): such ecotypes of common bottlenose dolphins exist in the western North Atlantic (Hersh \& Duffield 1990, Torres et al. 2003) and possibly in the Mediterranean (Kerem et al. 2013). In fact, stable coastal groups of bottlenose dolphins inhabit the northern Black Sea (Bel'kovich 1978, Gladilina et al. 2013), whereas large aggregations are also recorded in the offshore waters (Mikhalev 2005). Support for this hypothesis is the polymodal distribution of body lengths reported by Barabash-Nikiforov (1940) from the data 


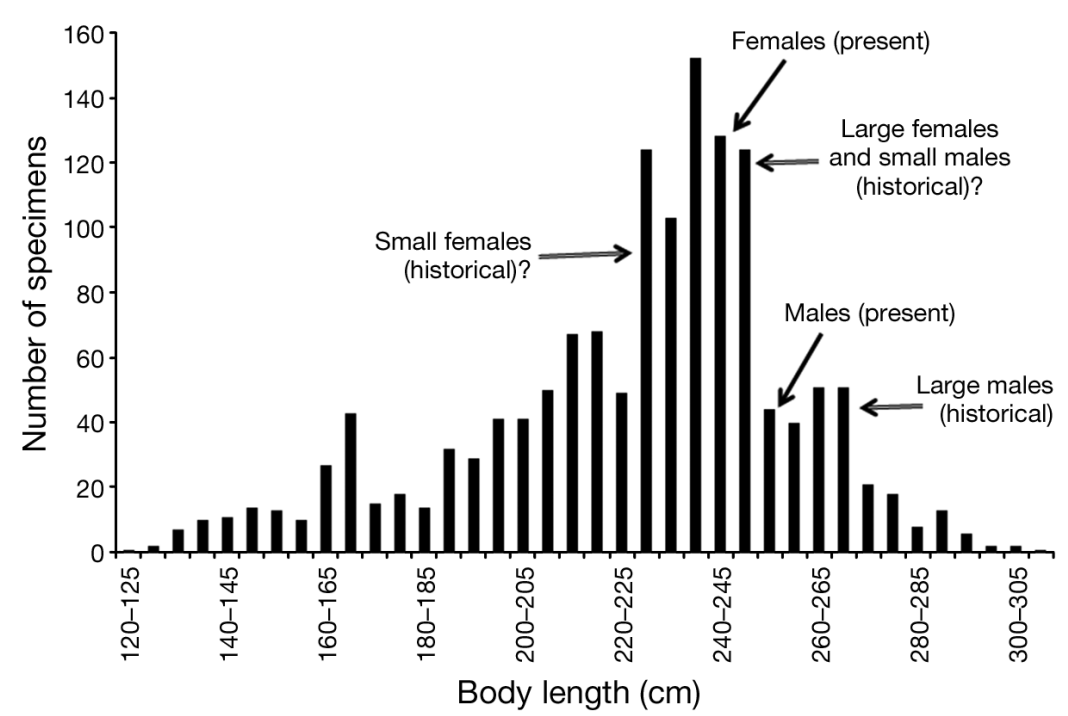

Fig. 5. Historical size structure of Black Sea bottlenose dolphins in the 1930s (data from Barabash-Nikiforov 1940) with the extrapolated present-day values for overall samples of adult females and males. Three peaks are seen in the historical body length distribution of adult dolphins, which can be identified as small females, combined large females + small males and large males

\section{Dwarfism and geographical variation}

Present-day Black Sea bottlenose dolphins are distinctly smaller than representatives of any Mediterranean stock of bottlenose dolphins. Adult dolphins from the Levantine waters of Israel are on average $15 \mathrm{~cm}$ longer than Black Sea dolphins (Kerem et al. 2013), and other Mediterranean dolphins are even larger (Sharir et al. 2011), as are common bottlenose dolphins from the North Atlantic, South Atlantic and Indo-Pacific (Cockcroft \& Ross 1990, Hale et al. 2000, Siciliano et al. 2007). However, note that the historical large morph (BarabashNikiforov 1940) is similar in size to the dolphins from the geographically close Mediterranean regions, namely the Levantine basin (Kerem et al. 2013) and the Adriatic Sea (Pribani et al.

from direct takes (Fig. 5). There are 3 peaks in the body length distribution of small-sized animals, corresponding to calves $(145-150 \mathrm{~cm}), 1 \mathrm{yr}$ old animals $(165-170 \mathrm{~cm})$ and sub-adult dolphins $(210-220 \mathrm{~cm})$. In addition, there are 3 size peaks corresponding to adults (rather than the two, i.e. female and male, which one would expect): 225-230, 240-250 and $260-270 \mathrm{~cm}$. The existence of these 3 peaks is supported by the mixture model with the minimum value of AIC $=150$ (Hammer et al. 2001). Notably the middle of these peaks is the highest, as if it contained modal classes of a few groups. Therefore, it is possible that 2 morphs co-exist in the Black Sea:

(1) a large (offshore) form with a mean length of ca. $275 \mathrm{~cm}$ (and maximum length up to $330 \mathrm{~cm}$ ) in adult males and 245-250 cm in adult females, and

(2) a small (coastal) form with the mean length of ca. $245 \mathrm{~cm}$ in adult males and ca. $230 \mathrm{~cm}$ in adult females.

Present-day dolphins in our sample are on average slightly larger than the small form from the size structure reported by Barabash-Nikiforov (1940) (Fig. 5). This variation may be due to the following processes: (1) descendants of the small-sized stock have become larger due to density-dependent regulation of individual body size, (2) descendants of the large-sized stock have become smaller after the population 'bottleneck' events, or (3) present-day dolphins are a mix of the 2 historical morphs. The larger morph possibly includes winter-breeding migrants or immigrants from the Mediterranean Sea.
2000; see also the review by Sharir et al. 2011). Furthermore, dolphins from the coastal waters of the Gulf of Mexico and Florida are similar in size to present-day Black Sea animals (Fernandez \& Hohn 1998, Stolen et al. 2002, Mattson et al. 2006): the smallest adult common bottlenose dolphins, ca. $200 \mathrm{~cm}$ long, were reported from the Mississippi coast (Mattson et al. 2006). Thus, Black Sea bottlenose dolphins are within the size range of Tursiops truncatus.

Possible factors driving decrease in body size in bottlenose dolphins in certain geographical areas were reviewed by Sharir et al. (2011): hypothetically, low productivity, high salinity and high water temperature could contribute to the small size of dolphins in the Levantine basin. However, the Black Sea is characterized by distinctly low salinity $(18 \%)$, temperate climate (mean August temperature is $24^{\circ} \mathrm{C}$ and mean winter temperature $7^{\circ} \mathrm{C}$ ) and moderate productivity (primary production is 0.5 to $0.8 \mathrm{~g} \mathrm{~cm}^{-2} \mathrm{~d}^{-1}$ ). Therefore, none of the 3 factors presented by Sharir et al. (2011) explain the smaller size of Black Sea dolphins. Notably, other cetacean species also attain small size in the Black Sea. An example is the harbour porpoise Phocoena phocoena in the Atlantic, which generally follows an opposite pattern predicted by the Bergmann rule: porpoises on average become larger from the north to the south (Galatius \& Gol'din 2011). However, the porpoises in the Black Sea break with this trend, reaching the smallest body length (115 to $120 \mathrm{~cm}$ ) within the species' entire distribution range (Gol'din 2004). 
Other factors that could hypothetically affect the body size are the coastal habitat (rather than offshore) and the enclosed sea area (rather than an ocean) (Perrin 1984). The Black and Mediterranean Seas, as well as the coastal waters of the Gulf of Mexico, combine both conditions. In addition, these regions are characterized by low or moderate (but not high) productivity. However, there is another, purely geographical, factor at work in the Black and Mediterranean Seas: body size diminishes in marginal populations regardless of other natural conditions, and it reaches its extreme manifestation in the most remote and isolated population in the coastal Black Sea waters (Fig. 6).

This phenomenon resembles the 'island rule' where dwarfism is evident in insular populations of ungulates and some carnivores (Foster 1964, Lomolino 2005). Although mostly studied in land ecosystems, the island rule has also been applied to some marine zones (McClain et al. 2006). For terrestrial carnivores, decline in body size was explained as an effect of lower resource base (Raia \& Meiri 2006) or a lower optimal size as a function of a smaller prey size (Case 1978). The first explanation evidently fails for cetaceans in coastal waters with high productivity (and hence fish production [Ryther 1969]); this applies in particular to the very productive Gulf of Mexico. However, the hypothesis of prey size effect seems promising at least for the Black Sea and the Levantine basin. 'Levantine nanism', the small size of many eastern Mediterranean hydrobionts, has been recorded for many taxa, including fish species, which are prey for dolphins: bandtooth conger Ariostoma balearicum, sand steebras Lithognathus mormyrus, bogue Boops boops, etc. (Edelist et al. 2014, Scheinin et al. 2014). The Black Sea bottlenose dolphins were recently shown to feed on notably small-sized prey such as horse mackerel Trachurus meditrraneus, picarel Spicara flexuosa, sprat Sprattus sprattus, anchovy Engraulis encrasicolus (Gladilina \& Gol'din 2014).

A necessary disclaimer is that our sample consisting of stranded animals can be unrepresentative of the whole population (or populations). For example, coastal dolphins may be more likely to strand, whereas the carcasses of the largest offshore dolphins remain in the sea. On the other hand, large carcasses decompose more slowly and thus are more likely to be washed ashore. In addition, it is unknown if there are morphological and genetic differences between several coastal stocks inhabiting the area of study (Gladilina et al. 2013). Finally, the small sample used in this study is a compromising factor. Nevertheless, the occurrence of a few very small dolphins (especially among adult females) even in the limited sample supports our argument.

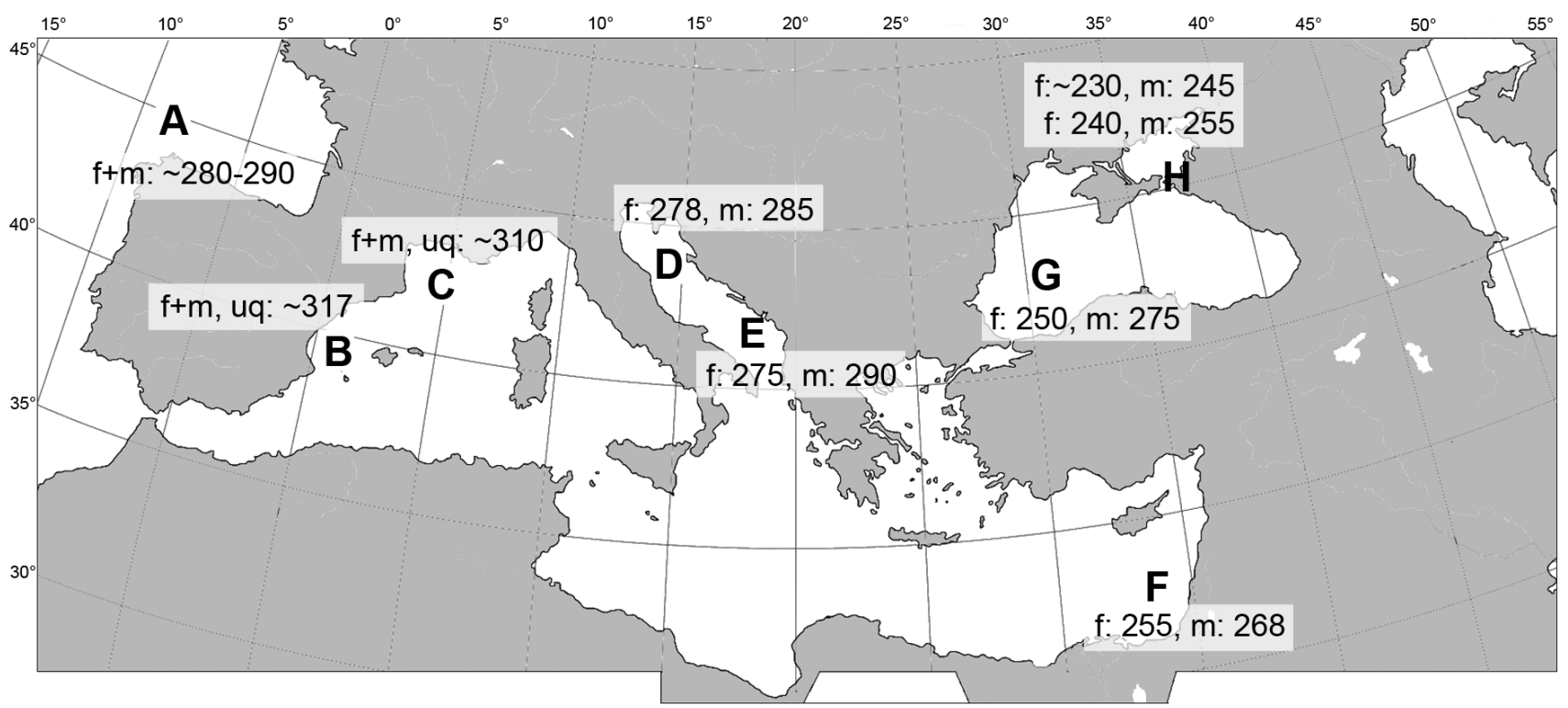

Fig. 6. Geographical distribution of average body lengths (in $\mathrm{cm}$ ) of adult common bottlenose dolphins. $\mathrm{f}$ : females; m: males; $\mathrm{f}+\mathrm{m}$ : both sexes combined; uq: upper quartile value instead of the average length. A: Atlantic waters of north-west Spain (Santos et al. 2007); B: Mediterranean waters of Spain (Sharir et al. 2011); C: Mediterranean waters of France (Sharir et al. 2011); D: northern Adriatic Sea (Pribanić et al. 2000); E: southern Adriatic Sea (Butti et al. 2007); F: Levantine basin, Israel (Kerem et al. 2013); G: historical offshore population of the Black Sea; H: historical and present-day coastal population of the Black Sea 

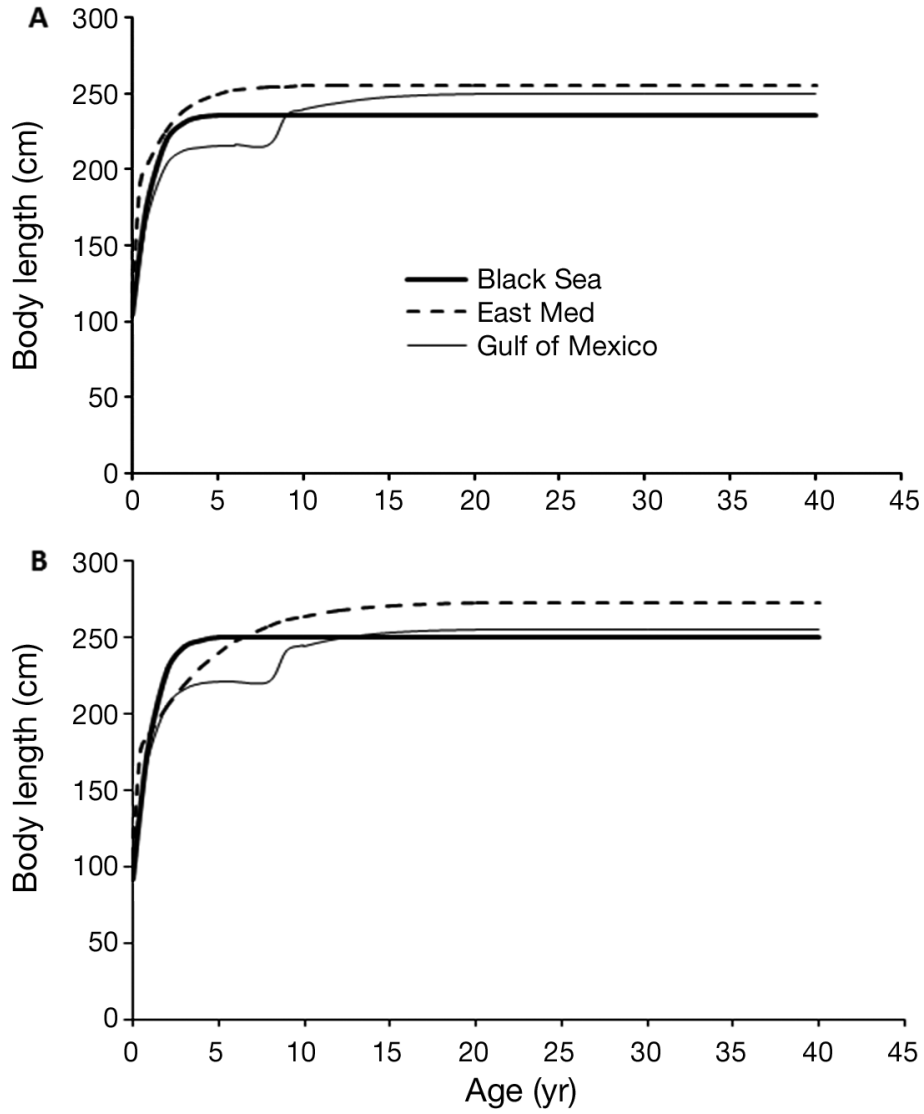

Fig. 7. Geographical variation in growth curves of common bottlenose dolphins. A: females; B: males. Data on the eastern Mediterranean are from Kerem et al. (2013), data on the Gulf of Mexico are from Mattson et al. (2006) growth curve is a manifestation of an extremely reproduction-oriented life history of a marine mammal.

Thus, growth strategies of Black Sea bottlenose dolphins of both sexes may be associated with early growth and maturation, and this may be a mechanism leading to their smaller size. Further research of this mechanism could be directed towards the study of ontogenetic trajectories (with their heterochronic aspects) and the details of reproductive biology, namely the age of sexual maturity, duration of the reproductive period and reproductive rate and success.

Acknowledgements. We sincerely thank Karina Vishnyakova, Andrey Kondakov, Andrey Averichev, Yury Musienko and Alla Morozova for their help and support in organization of the field expeditions; Evgeny Gol'din and Andrey Artov who kindly provided data on the strandings recorded in 1997; Kseniya Kirukh, Dmitry Smirnov, Evgeny Kushnir, Yury Lyashenko, Oksana Savenko, Olga Shlyakhova, Dmitry Markov, Evgeny Oleinikov, Oleg Kukushkin, Roman Zimnukhov, Roman Gladilin, Dmitry Startsev, Ilya Nurpeisov, Marina Chopovdya, Anastasiya Kolesar, Alexey Ivanov, Sergey Kondakov, Evgeny Gol'din and Darya Lisyanskaya for participation in the field studies or information on the findings; Lyudmila Bogdanova and Dan Kerem for the discussion of life history and growth; Igor Dzeverin for the recommendations on statistical analysis; Lena Godlevska for the help with the map design; and 3 anonymous reviewers for their numerous constructive comments on the earlier draft of the manuscript.

\section{Life-history strategies}

The growth trajectory of the Black Sea female dolphins is very similar to that of conspecifics in eastern Mediterranean waters of Israel (Fig. 7): rapid early growth and fast attainment of the relatively small asymptotic size. However, the environmental conditions in the eastern Mediterranean, which were suggested as possible causes of such an early maturation of females (Kerem et al. 2013), are substantially different from the Black Sea: the Levantine basin is warmer, less productive and more saline. Meanwhile, the male growth curve is closer to that of the dolphins from the Mississippi region of the Gulf of Mexico (data by Mattson et al. 2006) (Fig. 7), and it is also distinct in rapid early growth and maturation. Thus, growth rates for both sexes, as indicated by $k$ values in the Gompertz equation, are extremely high in comparison with other populations (Kerem et al. 2013). Given a small adult body size, such a

\section{LITERATURE CITED}

Barabash-Nikiforov II (1940) Cetacean fauna of the Black Sea, its composition and origin. Izd-vo Voronezh. Gos. Un-ta, Voronezh (in Russian)

Bel'kovich VM (1978) Behaviour and bioacoustics of dolphins. Shirshov Institut Okeanologii AN SSSR, Moscow (in Russian)

Bogdanova LN (2006) Seasonal and age depending changes of sex hormones in the Black Sea bottlenose dolphins in captivity. In: Bel'kovich VM (ed) Marine mammals of the Holarctic. Collection of Scientific Papers. St. Petersburg, p 98-101

Butti C, Corain L, Cozzi B, Podestà M, Pirone A, Affronte M, Zotti A (2007) Age estimation in the Mediterranean bottlenose dolphin Tursiops truncatus (Montagu 1821) by bone density of the thoracic limb. J Anat 211:639-646

Case TJ (1978) A general explanation for insular body size trends in terrestrial vertebrates. Ecology 59:1-18

Cockcroft VJ, Ross GJB (1990) Age, growth, and reproduction of bottlenose dolphin Tursiops truncatus from the east coast of Southern Africa. Fish Bull 88:289-302

Edelist D, Golani D, Spanier E (2014) First implementation of the Large Fish Index (LFI) in the eastern Mediterranean. Sci Mar 78:185-192 
Fernandez S, Hohn AA (1998) Age, growth and calving season of bottlenose dolphins, Tursiops truncatus, off coastal Texas. Fish Bull 96:357-365

Foster JB (1964) Evolution of mammals on islands. Nature 202:234-235

Galatius A, Gol'din PE (2011) Geographic variation of skeletal ontogeny and skull shape in the harbour porpoise (Phocoena phocoena). Can J Zool 89:869-879

Gladilina EV, Gol'din PE (2014) New prey fishes in diet of Black Sea bottlenose dolphins Tursiops truncatus (Mammalia, Cetacea). Vestnik Zoologii 48:83-92

Gladilina EV, Lyashenko YuN, Gol'din PE (2013) Winter distribution of cetaceans in the Black Sea and adjoining areas in 2012/2013. Sci Notes Taurida Vernadsky Nat Univ Ser Biol Chem 26(1):37-42

Glazov DM, Lyamin OI (2000) Observations of dolphin strandings along the Black Sea coast of Caucasus. In: Marine mammals of the Holarctic. Materials of International Conference. Arkhangelsk, p 87-90 (in Russian)

Gol'din PE (2004) Growth and body size of the harbor porpoise Phocoena phocoena (Cetacea, Phocoenidae) in the Sea of Azov and the Black Sea. Vestnik Zoologii 38:59-73

Gol'din PE (2006) On the lifespan of the Black Sea bottlenose dolphin (Tursiops truncatus) in natural populations. In: Bel'kovich VM (ed) Marine mammals of the Holarctic. Collection of Scientific Papers. St. Petersburg, p 153-154

Hale PT, Barreto AS, Ross GJB (2000) Comparative morphology and distribution of the aduncus and truncatus forms of bottlenose dolphin Tursiops in the Indian and Western Pacific Oceans. Aquat Mamm 26:101-110

Hammer Ø, Harper DAT, Ryan PD (2001) PAST: Paleontological Statistics Software Package for Education and Data Analysis. Palaeontologia Electronica 4(1). http:// palaeo-electronica.org/2001_1/past/issue1_01.htm

Hersh SL, Duffield DA (1990) Distinction between Northwest Atlantic offshore and coastal bottlenose dolphin based on hemoglobin profile and morphometry. In: Leatherwood S, Reeves RR (eds) The bottlenose dolphin. Academic Press, San Diego, CA, p 129-139

Herzing DL (1997) The life history of free-ranging Atlantic spotted dolphins (Stenella frontalis): age classes, color phases, and female reproduction. Mar Mamm Sci 13:576-595

Karaçam H, Düzgüneş E, Durukanoğlu HF (1990) A study on the age-weight, age-length composition of dolphins and porpoises in the Black Sea. Istanbul Univ J Aquatic Produc 4:35-44 (in Turkish)

Kastelein RA, Dokter T, Zwart P (1990) The suckling of a bottlenose dolphin calf (Tursiops truncatus) by a foster mother, and information on transverse birth bands. Aquat Mamm 16:134-138

Kerem D, Kent R, Roditi-Elasar M, Goffman O, Scheinin A, Gol'din P (2013) Early physical maturation of female common bottlenose dolphin Tursiops truncatus in the eastern Levantine Basin. Israel J Ecol Evol 59:154-162

Kleinenberg SE (1956) Mammals of the Black Sea and the Sea of Azov: an experience of biological and fisheries research. Izdatelstvo AN SSSR, Moscow (in Russian)

Klevezal GA (1988) Registering structures of mammals in zoological research. Nauka, Moscow (in Russian)

Lomolino MV (2005) Body size evolution in insular vertebrates: generality of the island rule. J Biogeogr 32:1683-1699

Mattson MC, Mullin KD, Ingram GW, Hoggard W (2006) Age structure and growth of the bottlenose dolphin (Tursiops truncatus) from strandings in the Mississippi Sound region of the north-central Gulf of Mexico from 1986 to 2003. Mar Mamm Sci 22:654-666

McClain CR, Boyer AG, Rosenberg G (2006) The island rule and the evolution of body size in the deep sea. J Biogeogr 33:1578-1584
McFee WE, Schwacke JH, Stolen MK, Mullin KD, Schwacke LH (2010) Investigation of growth phases for bottlenose dolphins using a Bayesian modeling approach. Mar Mamm Sci 26:67-85

Mead JG, Potter CW (1990) Natural history of bottlenose dolphins along the central Atlantic coast of the United States. In: Leatherwood S, Reeves RR (eds) The bottlenose dolphin. Academic Press, San Diego, CA, p 165-195

Mikhalev YuA (2005) The peculiarities of the distribution of the bottlenose dolphin, Tursiops truncatus (Cetacea), in the Black Sea. Vestnik Zoologii 39:29-42 (in Russian)

Norris KS (1961) Standardized methods for measuring and recording data on the smaller cetaceans. J Mammal 42: $471-476$

Ozharovskaya LV (1997) Reproduction of the Black Sea bottlenose dolphin. In: Sokolov VE, Romanenko VV (eds) Black Sea bottlenose dolphin Tursiops truncatus ponticus. Morphology, physiology, acoustics, hydrodynamics. Nauka, Minsk, p 114-145 (in Russian)

Perrin WF (1984) Patterns of geographical variation in small cetaceans. Acta Zool Fenn 172:137-140

Pribanić S, Mioković D, Kovačić D (2000) Preliminary growth rate and body lengths of the bottlenose dolphins Tursiops truncatus (Montagu, 1821) from the Adriatic Sea. Natura Croat 9:179-188

Raia P, Meiri S (2006) The island rule in large mammals: paleontology meets ecology. Evolution 60:1731-1742

Ryther JH (1969) Photosynthesis and fish production in the sea. Science 166:72-76

Santos MB, Fernandez R, Lopez A, Martinez JA, Pierce GJ (2007) Variability in the diet of bottlenose dolphin, Tursiops truncatus, in Galician waters, north-western Spain, 1990-2005. J Mar Biol Assoc UK 87:231-241

> Scheinin AP, Kerem D, Lojen S, Liberzon J, Spanier E (2014) Resource partitioning between common bottlenose dolphin (Tursiops truncatus) and the Israeli bottom trawl fishery? Assessment by stomach contents and tissue stable isotopes analysis. J Mar Biol Assoc UK 94:1203-1220

Sharir Y, Kerem D, Gol'din P, Spanier E (2011) Small size in the common bottlenose dolphin Tursiops truncatus in the eastern Mediterranean: a possible case of Levantine nanism. Mar Ecol Prog Ser 438:241-251

Siciliano S, Ramos RMA, Di Beneditto APM, Santos MCO and others (2007) Age and growth of some delphinids in south-eastern Brazil. J Mar Biol Assoc UK 87:293-303

Stolen MK, Odell DK, Barros NB (2002) Growth of bottlenose dolphins (Tursiops truncatus) from the Indian River Lagoon system, Florida, USA. Mar Mamm Sci 18:348-357

Tomilin AG (1957) Cetaceans. Animals of the USSR and adjacent countries, Vol 9. Izdatelstvo Akademii Nauk SSSR, Moscow (in Russian)

> Torres LG, Rosel PE, D'Agrosa C, Read AJ (2003) Improving management of overlapping bottlenose dolphin ecotypes through spatial analysis and genetics. Mar Mamm Sci 19: 502-514

> Urian KW, Duffield DA, Read AJ, Wells RS, Shell ED (1996) Seasonality of reproduction in bottlenose dolphins, Tursiops truncatus. J Mammal 77:394-403

- Viaud-Martinez KA, Brownell RL Jr, Komnenou A, Bohonak AJ (2008) Genetic isolation and morphological divergence of Black Sea bottlenose dolphins. Biol Conserv 141:1600-1611

Wells RS, Scott MD (1999) Bottlenose dolphin Tursiops truncatus (Montagu, 1821). In: Ridgway SH, Harrison R (eds) Handbook of marine mammals, Vol 6. Academic Press, San Diego, CA, p 137-182

- Würsig B (1978) Occurrence and group organization of Atlantic bottlenose porpoises (Tursiops truncatus) in an Argentine bay. Biol Bull 154:348-359 